\title{
About the Early International Congresses of Applied Mechanics
}

\author{
Giovanni Battimelli
}

\section{A. Summary}

Several authors have discussed the conflict, during and after the first world war, between the internationalist ideology of scientific knowledge and the political commitment of scientists, in particular with regard to the policy of the International Research Council and of its scientific unions. A case study is presented here of an international body which was born during the Twenties (when the polemic between scientists on opposite sides was at its peak) and quickly attained unpredicted success. Preceded by an informal gathering organized by T. von Karman and T. Levi-Civita in Innsbruck in 1922, the International Congress of Applied Mechanics, first held in Delft in 1924, was, at the end of the decade, much more of a live institution than many of the unions tied to the IRC.

Two factors seem to be especially responsible for this success: On one hand, the programmatic refusal by the "founding fathers" to establish any formal connection between the Congress and any official body or institution tied to the IRC or to single governments, in order to avoid the obstacles of international scientific diplomacy. This "refusal of politics" proved to be an extremely successful political act. On the other hand, the specific nature of the discipline involved has to be taken into account. The International Congress of Applied Mechanics is seen as the body which comes to identify a new sector of scientific activity, bordering on physics, mathematics, and engineering, which took shape in those years mainly in the German-speaking scientific world.

It may be recalled that proposals advanced at the IRC to establish international cooperation on technical matters, tied as they were to old-fashioned disciplinary

\footnotetext{
G. Battimelli $(* 1948)$

Universita degli Studi di Roma "La Sapienza", Rome, Italy

(C) The Author(s) 2016

P. Eberhard and S. Juhasz (eds.), IUTAM,

DOI 10.1007/978-3-319-31063-3_4
} 
subdivisions, and generally inspired by anti-German prejudice, totally failed to materialize.

\section{B. Prehistory: Innsbruck Conference}

In April 1922, the director of the Aerodynamical Institute of the Aachen Polytechnic, Theodore von Karman, wrote to the Italian mathematician Tullio Levi-Civita in Rome, asking for his advice and collaboration on a project he was considering. Karman noted the contrast between the rapid development taking place and the interesting new results being obtained at the time in the field of hydro- and aeromechanics, on one hand, and on the other the little space devoted to such problems at scientific meetings, and the scarcity of personal contacts between scientists engaged in the field. Moreover, Karman added, people interested in fluid mechanics attended either mathematical, or physical, or technical conferences thus limiting even more the possibility for closer interaction. Time was ripe, in Karman's judgement, to break this dependence from the mother disciplines and to give hydro- and aeromechanics the independent status they deserved. How would Levi-Civita assess the prospect of calling an informal meeting of people interested in the field, both from the theoretical and the experimental sides? Karman suggested holding the meeting in Innsbruck in the fall and asked for the Italian's collaboration as co-organizer.

Karman had more than one reason for choosing Levi-Civita, among others, as a partner for the enterprise, apart from their good personal relations. To obtain the best result in terms of international participation, it could be a good move to have as one of the organizers, besides the Hungarian-born von Karman, a leading scientist from one of the Allied Powers, well known for his pacifist and internationalist views. Karman could take care of securing the attendance of German scientists and Levi-Civita could smooth hesitation and resistance that had to be expected from the side of the wartime victors, especially from the French. Also, apart from diplomatic considerations, Levi-Civita was a sound scientific choice. He was basically a pure mathematician; his association with Karman as promoter of a conference on technical matters was a living example of how Karman meant to develop the field, maintaining close connections between technical developments and the empirical work and the more fundamental theoretical research and a high level of mathematical sophistication.

Levi-Civita's answer was warmly enthusiastic, and he especially noted the importance of obtaining as international a participation as possible. "I think"-he wrote back to Karman - "that we should send the invitation also to some English and French scientists... Should any of them actually come, so much the better; in any case it will be clear that we are moved by a spirit of scientific internationalism."

With the material organization of the meeting in his and Levi-Civita's hands, Karman looked around for other renowned scientists to establish a sort of scientific committee and sign the invitation to be sent out. A draft of the invitation letter can be seen in the following. It was easy for him to secure the adhesion of his former teacher, Ludwig Prandtl from Göttingen, but with an eye to diplomacy he felt that 
he needed someone from the former neutral countries. Writing to Stodola, the turbine expert in Zurich, he said that "political views should be completely bypassed by the fact that the meeting will not represent any official congress, but will be held as a totally informal gathering."

wonsieur et cher colltgal,

Un groupo de savants et d'1ng bnleurs $s^{-1}$ cccupant

difydroaynamique et a keroabcan1que a a

d'une potite róunion sclentiplque de porsonnes intrêssos

a cette branche de la science.

Dans tous les pays, 1 Hydrodyaanique a Palt

dernisrefoneptes progres 10rortants, tant ce gul concerne

les thsorito classlques tant en sluoldant et fproponalssant

les probldmes fondasentaux de 1 'Hydraul1 1 , ue pact

de 1 'Nerotechn1que; aale les franements polltibues ont

eapech leschange des 1 dése ot des expériencos.

Cetce petite róunion para sera kestinso a ressedbler

quelques savants et lingśnleurs intsreess a ces probldzes

afón a'schenger leurs vues scientiligues.

On fera des conférences sur les grogrde réallabs

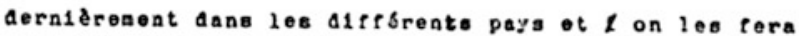

sulve de descussicns.

Hous avone 1 'honneur ae vous invitez a prendre part

d cette resunion gui aura liou a Innebruck ( 11 rol) du

10. 13. September 1922 .

S1 vous approuver notre 116e, veulllek envoyer un nct

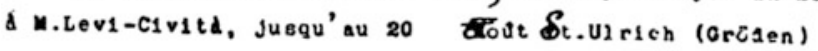

(Alto Adige, Jtalle) Hotel Post, Papere Via Altinis:e

od d M.de rárzán, Institut aerodynaeligue Aachen (Allezagne).

M. Ae Kárzán se tlent a votro disposition pour toua lec

reneelenements concernent 1 , Itinoralre, logezents etc.

Voue receverez bientot un progranse dotallis avec lec

titres des conérences et les sujets des alscuspione.

Veulllez aggrser, Munclour et cher collague, lasirance

de nca sentianta tros distinguso.

T.Levi-Civita c. v.0eecen L.Prantel

Th. de Kárzán

In fact, however, Karman worried about possible difficulties arising from political views much more than he was willing to admit. The letter he sent to H.A. Lorentz clearly shows it: "It would be of great importance,"- 
leading Dutch scientist - "that the invitation to this informal conference, which by no means will have the character of an official congress, be signed by some scientist from the neutral countries... May I stress that, even if by misfortune you could not come to Innsbruck, it would be important for us to have, all the same, your signature." Lorentz was, in fact, prevented from attending the meeting, and therefore politely declined the invitation to sign the conference announcement, which finally was signed by Karman, Levi-Civita, Prandtl, and the Swedish physicist, C.W. Oseen, from Uppsala. Meanwhile, Levi-Civita was trying to obtain the adhesion to the conference of "Mr. Italian Science," Vito Volterra, writing him a letter that presented the whole thing as having been originated by Oseen, with the Germans being there by mere chance. Volterra's strong nationalistic views were well known, and he was at the time the leader of the Italian delegates to the International Research Council, whose policy was primarily inspired by anti-Germanism. His adhesion would obviously have been of great significance, but Volterra did not fall into Levi-Civita's trap and rather harshly replied that he could neither attend the meeting nor give his adhesion.

The difficulties that the two organizers expected began to appear. Two quotations will suffice to give an idea of the atmosphere. On one hand, Marcel Brillouin replied to Levi-Civita: "Meetings such as this, even more than the international congresses, require as a condition the absence of any suspicion that might hinder cordiality. As far as I am concerned, until the German scientists and professors will understand that, in order not to pay for reparations, one should first of all not have caused systematic destruction - and that such destruction having been caused, the Germans must pay for them - my esteem for their moral character is not high enough to allow me to shake hands with them, whatever their indisputable scientific merits." And on the other hand, Richard von Mises wrote back to Karman: "You will not be surprised by the fact that I will not come, since my views about Tyrol and the Italians are well known to you... Furthermore, I am a bit surprised at seeing that German professors feel the need to communicate abroad their theoretical researches on flight, while we are at the same time prevented from building real airplanes."

These statements are quite typical of the sort of accusations and complaints that bounced at the time from each side against the other. They were not, however, the only kind of response with the exception of France and Britain, where clearly people felt that, despite Levi-Civita's presence, the whole thing was too firmly in German, or German-controlled, hands. Elsewhere, the general reaction was a favorable one, and the final list of adhesions included most of the outstanding names in the field. Meteorologists Bjerknes and Ekman came from Norway. Sommerfeld, though prevented from attending in person, sent his student, Heisenberg, to report on the research on turbulence he was doing for his dissertation. Even among the French scientists, there were those who sent messages of sympathy and adhesion, while lamenting that circumstances at home made it impossible for them to be present at the meeting. As can be seen on the displayed handwritten list of participants, thirty-three scientists gathered in September in Innsbruck, coming from Germany, Austria, Holland, Scandinavia and Italy, for what was unanimously regarded as a highly successful conference. 
Ifydro-aerodynam ische Koxferenz

Frnobrick 1922

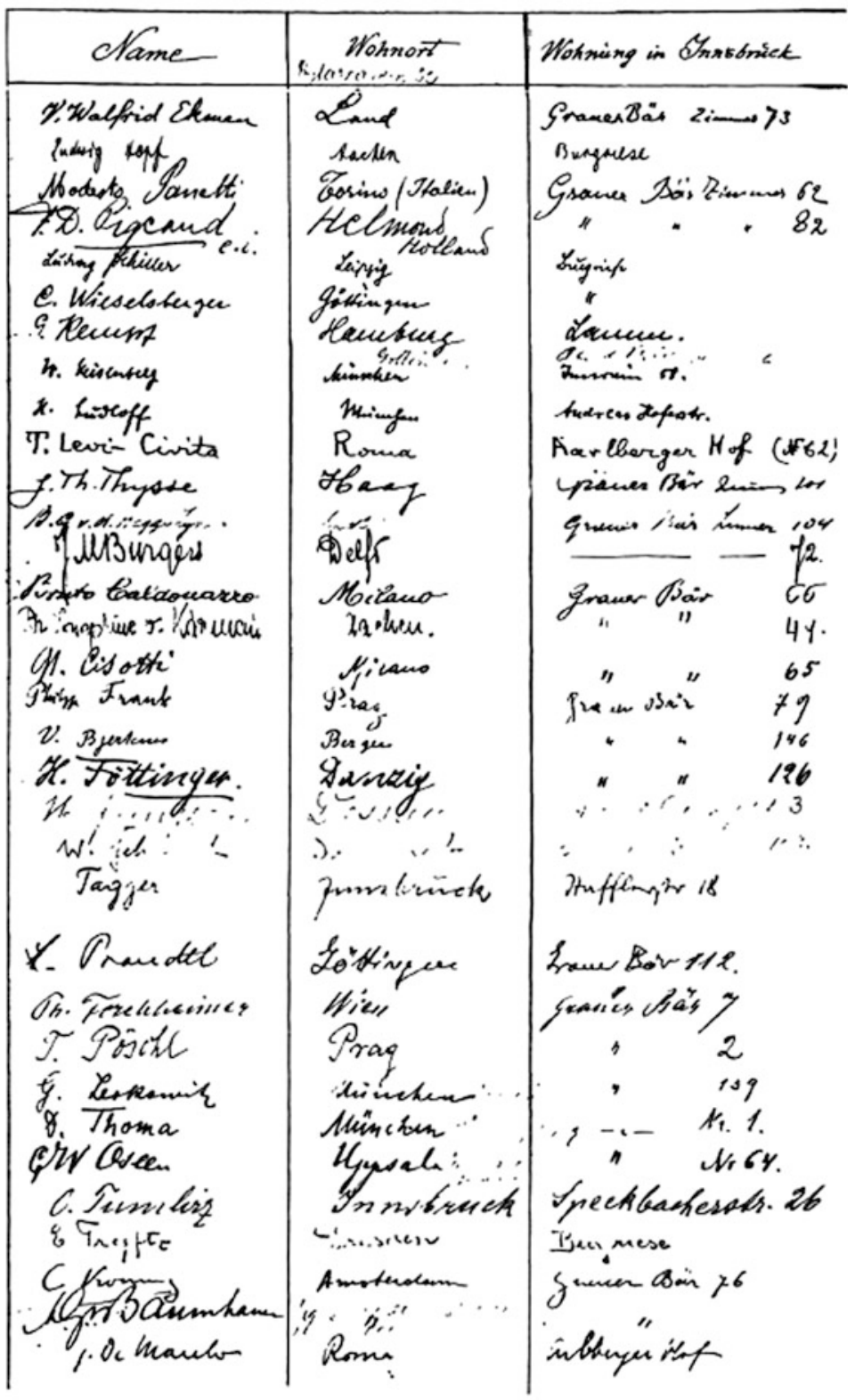




\section{First Congress-Delft}

Karman looked forward. Innsbruck was to him but the first step toward a more ambitious goal. He found a new, enthusiastic partner in one of the young scientists who had been at Innsbruck, the former student of Ehrenfest, Jan Burgers. They discussed the prospect of calling a wider conference, no longer restricted to hydroand aerodynamics, but embracing the whole field of applied mechanics. The Technical University of Delft, where Burgers held the chair of fluid mechanics, was identified as a proper place for the meeting, located, as it was, in a neutral country. Burgers and his friend and colleague Biezeno, the expert in elasticity theory, began again, with Karman's collaboration, the diplomatic ballet to form an Executive Committee as international as possible. Again, the winning card was expected to be the reasserted totally informal character of the conference. This worked; in fact, the number of nations represented in the Executive Committee grew from the six who were present in Innsbruck to ten, particularly notable being the adhesion of Ames and Hunsaker from the United States and of Taylor, Stanton, Griffith, and Coker from Britain.

Problems arose, however, with the two main antagonists, Germans and French. Invitations were sent to join the Committee to four French scientists, who either ignored or refused the proposal. Meanwhile, Prandtl and von Mises let it be known that they did not want any contact with the French, and they stated this as a condition for their adhesion to the Committee. Karman was rather upset by what he termed the "Katz- und Mausspiel" (cat and mouse game) between German and French scientists and tried quite firmly to let Prandtl understand that not only he did not share his teacher's and von Mises' views, but that he also regarded their position as being politically and scientifically shortsighted and wrong. "I wish to remark"- he wrote to Prandtl in December 1923, "that if the Congress will be held under these circumstances (one could say with the participation of all nations but France), this would represent an essential improvement for the official recognition of German science in the whole world, and I think that to withdraw in this case would be a completely wrong move from our side."

The solution of the impasse came as a result of the spontaneous withdrawal of the French. However, despite their absence, the Congress held in April 1924, turned out to be an unexpected success. It was made more remarkable by the fact that even a Belgian scientist attended the Congress (and was immediately co-opted into the committee). Over 200 scientists were present at Delft, where 76 papers were read, spanning the whole spectrum from mathematical problems in rational mechanics to experimental results in material strength. Some of these papers still stand as landmarks in the history of applied mechanics, such as the work by the Russians Friedmann and Keller on the closure problem for the hierarchy of the hydro dynamical equations. Friedmann, too, was invited to join the committee, which established itself as the International Congress Committee. 


\section{Second and Third Congresses}

It was decided that the Congress would assemble every fourth year, with the second to be held in 1926 in order to obtain a differential of two years with the International Congresses of Mathematics. Again, stress was laid upon the fact that the Committee members acted only as individuals and by no means represented any institution; no official designations by academies or governmental agencies would be accepted, and the Committee would only grow by cooptation. And soon it grew: by the end of 1925, following a renewed invitation, four French scientists joined the Committee. (It may be recalled that only in June 1926, a resolution was voted by the IRC General Assembly to invite the former Central Powers to join an invitation that, by the way, was refused by the Germans).

Meanwhile, difficulties started to appear regarding the choice of the site of the next Congress. Both Italy and Switzerland had offered to host the meeting in 1926, in Rome and Zurich, respectively. Pressures exerted by the Germans, mainly by von Mises, led to a preference for Zurich as a safer choice, Switzerland being a former neutral country. Levi-Civita, therefore, renewed the invitation to host the Congress in Rome in 1930, but the deterioration of political relations between Italy and Germany at the time again led von Mises to remark that a decision to hold the meeting in Rome could possibly result in a boycott by the German scientists. He asked Karman to exert pressure on Levi-Civita to convince him to withdraw the invitation. Karman refused to do so; if there was anyone he didn't want to irritate, he replied, it was the Italians because Italy was the only former enemy country that had been in on the venture from the very beginning. Finally, an invitation was offered by Oseen to hold the meeting in Stockholm, and Sweden was chosen, with general relief, as the country that would host the 1930 Congress.

To raise spirits again, the Belgians came forward with a new idea: in 1930, an International Exposition would be held in Liege to celebrate the hundredth anniversary of Belgium's independence, and it was suggested, too, that scientific meetings be held on the same occasion. The Rector of the University of Liege, therefore, asked Oseen to turn over to the Belgians the organization of the third Congress. Reaction was strong this time, not only, as was to be expected, by the Germans, but by virtually everyone in the Committee. This proposal seemed, in fact, to endanger one of the basic rules the founding fathers had decided to adhere to, namely, the totally non-official character of the Congress. Commenting on this point in a letter to Oseen, Burgers and Biezeno remarked, "In total contrast with the Belgians, who seem to regard a political event as a good reason to call for a scientific meeting, we think that no occasion would be less appropriate to this purpose, if the aim is really to promote the personal cooperation between scientists of different countries... We cannot see in this proposal anything else but a destructive action against the principles and the goals of our organization."

The 1930 Congress, which eventually gathered in Stockholm, marked a peak of attendance, with about 600 scientists. At the end of the meeting, sixteen nations, virtually the totality of the scientific world, were represented in the International 
Committee. Over a decade characterized by exclusion and conflicts between scientists and scientific institutions on opposite sides, the original project of von Karman, Levi-Civita, Burgers, and their colleagues had developed into an astoundingly successful international enterprise.

\section{E. International Relations in Sciences After WWI}

The story of this particular success seems to lend further evidence in support of some general features of international relations in science after World War I that have been pointed out by several authors in recent times. These include the fact that informal gatherings and freelance organizations had a chance of success, whereas the resumption of official international collaboration was blocked by political and diplomatic obstacles. Also the clash between the alleged international character of science and the national loyalty and political views of individual scientists could more easily be resolved when national and political considerations were, formally at least, left outside the door. Finally, the scientists from the neutral countries, mostly those connected with the German-speaking scientific community, played a fundamental role in leading Germany back into the international network.

\section{F. Nature of the Scientific Discipline: Applied Mechanics}

However, although the wise political conduct of the enterprise by Karman and colleagues may seem to suffice to account for the success met by their ambitious plan, a few more remarks about the nature of the specific discipline involved are in order. We are dealing here with applied mechanics, a discipline that simply did not exist, as a field in itself, before World War I. It was not simply a matter of resuming the international collaboration disrupted by the war in some established scientific field. In this case a new sector of the international scientific community was shaping its own identity by the very foundation of the Congresses. It is not surprising that the original idea of such a congress and the driving forces behind it came from scientists either in Germany or in those countries more closely connected to German scientific circles; it is in Germany that the need for, and the first steps toward, the establishment of applied mechanics as a separate field in itself began to appear right at the end of World War I. During and after the 1920 Naturforscherversammlung in Nauheim, some of the leading exponents of the field (Prandtl, von Karman, von Mises, Trefftz) had exchanged ideas and agreed on the conclusion that separate sessions for applied mechanics were needed at these meetings, distinct from those for mathematics and physics. This first happened the following year at the Naturforschertagung in Jena, which was prominently reported in a new journal that had appeared a few months 
earlier-the Zeitschrift für Angewandte Mathematik und Mechanik, edited by von Mises in Berlin, a journal that was soon to become the main reference and a favorite place of publication for researchers in that field.

There is abundant evidence, in the correspondence and in the personal recollections of the scientists we are discussing here, that they distinctly regarded themselves as the exponents of a new science, placed somewhere at the intersection between mathematics, physics, and engineering - the established disciplines in which most of them had their former training as scientists. The establishment of an international organization for applied mechanics also meant to emphasize this newly acquired identity of the discipline, going beyond the borders of Central Europe and giving it a marked worldwide character. Throughout the early life of the International Congresses, the founding fathers watched carefully that the scientific organization of the meetings should reflect the fundamental characteristic they meant to impress on their discipline, which may be summed up in the close connection between applied goals and theoretical research, empirical work and mathematical investigation: "turning engineering design into engineering science," as Karman used to put it. The 1924 meeting in Delft was divided into three main sections, one on hydro- and aerodynamics, the second on theory of elasticity, and the third on rational mechanics - thus stressing the importance of more theoretically oriented mathematical research for the development of the sectors more closely tied to practical applications. Two years later, when it appeared that the local Committee in Zurich meant to alter the name from "Applied Mechanics" to "Technical Mechanics" Burgers and Biezeno hastened to let Meissner know how much they disliked this prospect: "We have actually discussed the thing in detail in 1923, and we believe that the name now in use is to be preferred, because it embraces a wider field. For the development of mechanics, it is very important that the connection with the contiguous fields of mathematics and physics be maintained."

\section{G. Epilogue}

The advocacy of a tight link between the different facets of mechanics (always looking for the applicative goals, never neglecting the theoretical foundations) was clearly reflected throughout the inter-war years in the organization of the Congresses. A quick glance at the list of papers presented at each Congress will suffice to show how fundamental new theoretical results were reported alongside with significant technological advances. This spirit continued to be manifest in later years. In the mid-forties, the scientists had to face again a variety of obstacles to revive international collaboration in the new climate following the end of the second world war, with a changed political, institutional, and scientific environment; however, the basis on which the new scientific institution was formed remained the same. When the International Union came into existence, the adding of "Theoretical" to "Applied Mechanics" aptly stressed the fact that the old mark that had been impressed from the very beginning was still there. 
Open Access This chapter is distributed under the terms of the Creative Commons AttributionNoncommercial 2.5 License (http://creativecommons.org/licenses/by-nc/2.5/) which permits any noncommercial use, distribution, and reproduction in any medium, provided the original author(s) and source are credited.

The images or other third party material in this chapter are included in the work's Creative Commons license, unless indicated otherwise in the credit line; if such material is not included in the work's Creative Commons license and the respective action is not permitted by statutory regulation, users will need to obtain permission from the license holder to duplicate, adapt or reproduce the material. 